\title{
Biogeography of Korea's top predator, the yellow-throated Marten: evolutionary history and population dynamics
}

\author{
Michael Joseph Jowers ${ }^{1,2^{*}}$ (D, Santiago Sánchez-Ramírez ${ }^{3}$, Euigeun Song ${ }^{2}$, Samer Angelone ${ }^{4}$, Taeyoung Choi $^{2}$, \\ Inna Voloshina ${ }^{5}$ and Donggul Woo ${ }^{2}$
}

\begin{abstract}
Background: Peninsulas often harvest high genetic diversity through repeated southward migrations of species during glacial maxima. Studies addressing within-species evolutionary responses to climate fluctuations in northeast Asia are limited compared to other regions of the world, and more so in the Korean Peninsula. In this study, we conducted the first population-level study of the yellow-throated marten, Martes flavigula, from the Korean Peninsula, Russian, Taiwanese and Chinese localities in a biogeographic framework using mitochondrial $(c y t-b, n d 2, c r)$ and nuclear gene sequencing (ghr).

Results: Bayesian analyses revealed a rather young population, with a split from the most recent common ancestor at around 125 kya. Martes flavigula likely colonized the Korean Peninsula from Mainland China through the Yellow Sea twice, ca. 60 kya and 20 kya. Korean martens diversified during the Late Pleistocene with at least two dispersal events out of Korea, towards the southwest to Taiwan (ca. $80 \mathrm{kya}$ ) and towards the North into Russia and eastern China; most likely after the Last Glacial Maxima (ca. $20 \mathrm{kya}$ ). We argue that the lack of population structure and mixed populations is possibly a consequence of the high dispersal capability of the species. The Bayesian skyline plot revealed a population decline within the last 5000 years, suggesting potential negative biotic and anthropogenic effects in the area. We find that local populations are not genetically differentiated, therefore no perceptible population structure within Korea was found.

Conclusions: The topography and geography of the Korean Peninsula has played a pivotal role in its colonization. Connections between the Korean Peninsula and the Mainland through sea-level drops of the Yellow Sea at times of glacial maxima and the high dispersal capability of M. flavigula adds to the lack of geographical structure in this species and the paraphyly of Korean lineages.
\end{abstract}

Keywords: Martes flavigula, Korean Peninsula, Ice ages, Yellow Sea, Dispersal, Biogeography

\section{Background}

Present day species richness and distributions are believed to have been strongly influenced by the Last Glacial Maxima (LGM), patterns well documented throughout diverse European and North American studies [1-5]. At glacial maxima, peninsulas often have an important role, accumulating high genetic diversity

\footnotetext{
* Correspondence: michaeljowers@hotmail.com

${ }^{1} \mathrm{CIBIO} / \mathrm{InBIO}$ (Centro de Investigação em Biodiversidade e Recursos Genéticos), Universidade do Porto, Campus Agrario De Vairão, 4485-661 Vairão, Portugal

${ }^{2}$ National Institute of Ecology, 1210, Geumgang-ro, Maseo-myeon, Seocheon-gun, South Chungcheong province 33657, Republic of Korea Full list of author information is available at the end of the article
}

as a consequence of repeated migrations or expansions from northern localities $[1,6]$, and, at times, levels of genetic diversity can reflect high levels of endemism at the species or subspecies levels. In contrast, the overall species evolutionary responses to climate fluctuations in northeast Asia, and more precisely in the Korean Peninsula, are not fully understood [7]. The biogeographical history of the Korean Peninsula is complex due to intermittent mainland connections caused by global sea level changes [8-14]. Ice sheet formations in North Asia resulted in refugia $[15,16]$ in regions such as in the Korean Peninsula, but the LGM also facilitated connectivity throughout different periods by the

C The Author(s). 2019 Open Access This article is distributed under the terms of the Creative Commons Attribution 4.0 International License (http://creativecommons.org/licenses/by/4.0/), which permits unrestricted use, distribution, and 
drainage of the Yellow Sea resulting in land-bridge formations between the mainland and the Korean Peninsula $[8,9,17,18]$.

One interesting feature of the Korean Peninsula, from a biogeographical point of view, is that it is peripheral to some widely distributed Eurasian species, and therefore likely to hold genetic signatures through peripatric speciation events [19]. However, in the peninsula the only reported endemics have limited dispersal capability and high ecological specificity. Within the terrestrial vertebrates, only salamanders (Karsenia koreana, Onychodactylus koreanus, Hynobius quelpartensis, H. unisacculus, H. yangi) and frogs (Dryophytes suweonensis, Pelophylax chosenicus, Rana uenoi) are endemic, with a complete absence of endemic reptiles or mammals. Yet, phylogeographic and population genetic studies on small mammals reveal a strong genetic structure and unique lineages within the Korean Peninsula and adjacent areas. For example, molecular work on rodents, Apodemus peninsulae, A. agrarius, Myodes regulus, Tamias sibiricus and Crocidura shantungensis from the Korean Peninsula, China and Russia suggest that some areas within these regions likely acted as refugia during the Pleistocene [16, 20-23]. A few studies have addressed the complexity of the Pleistocene to better propose hypotheses on mammal distribution patterns throughout the Korean Peninsula, nearby Russia, eastern China and Japan [16, 24]. Some species are thought to have used the Korean Peninsula as a land bridge for mammals to cross to Japan up to $150 \mathrm{ky}$ BP before the sea started to rise and separated them for the last time [24-29]. Subsequent sea level drops in the Late Pleistocene and more recently throughout the LGM (23.5-18 cal. ka B.P.) indicate that the paleo-coastline would have connected the Korean Peninsula, southern China and Taiwan [30,31], allowing for new migration or expansion routes, but not to Japan [32].

Throughout the Holocene, China, Taiwan, the Korean Peninsula and Russia have undergone complex environmental changes to their coastline as a consequence to cyclical sea-level fluctuations [13, 33]. The Yellow Sea was under an estuarine environment until the mid-Holocene and geological studies suggest that the present marine conditions are therefore recent [9-12, 33]. Such land connections would have opened possible recent routes for dispersal from and to the Korean Peninsula, especially for mammals with large home ranges. Altogether, the expanding and contracting coastal area contributing to the connectivity and the isolation of new islands and the peninsula is likely to have had important consequences throughout the area. Evidence of periods of connectivity by marine regression derive from recent molecular work of the Asian badger (Meles leucurus) [34] and Sorex caecutiens [35] from the
Korean Peninsula and Jeju island in the South, showing limited divergence within the Peninsula and nearby localities.

Studies on larger mammals with broad home ranges such as the red fox (Vulves vulpes), the grey wolf (Canis lupus) and the raccoon dog (Nyctereutes procyonoides) in Korea, China and Russia have revealed a lack of geographical structure and unclear phylogeographic patterns within the region [16, 36-38]. Thus, species with high dispersal capabilities and little habitat specificity inhabiting regions with abrupt topographical changes and episodic land connectivity are expected to show little genetic differentiation over wide geographical ranges [39]. One such example is the genus Martes, found in Asia, Europe and North America, with species generally showing considerable distribution ranges. However, most eastern Eurasian marten species today exhibit a disjoint distribution, reflecting population fragmentation of former wider species ranges, possibly as a consequence of glaciation events throughout their range [40, 41]. Such fragmentation events may limit gene flow, eventually leading to allopatric speciation. The only species of marten present in the Korean Peninsula is the yellow-throated marten (Martes flavigula). The Korean Peninsula offers a unique model to assess patterns and processes, as it is part of the northern- and eastern-most distribution limit of the yellow-throated marten. This species is widely distributed throughout southern and eastern Asia, ranging from the Himalayas to southern China, the Malay Peninsula, Sunda Islands, Siberia and The Korean Peninsula [42-46]. Martes flavigula is believed to have originated in tropical regions and expanded to the northeast temperate areas such as Korea and Russia after the last glacial maximum (20-18 ky BP; $[47,48])$. Despite their wide distribution in both tropical and temperate zones, studies on their population structure and ecology remain scant compared to other species within the genus $[42,44,49,50]$. Phylogenetic work on $M$. flavigula has shown low genetic divergence $(0.3 \%)$ between Taiwan, Russia (Primorye), and South China (Kunming), and as in other mustelid species they are thought to have had complex colonization episodes of nearby areas [51]. However, there are limited data on the population structure and population demographics of the species within the Korean Peninsula $[52,53]$. Based on their wide home ranges [44], their high dispersal capability, and the presence of relatively recent land bridge connections from the Korean Peninsula to the mainland we expect the following: 1) an absence of population structure throughout the geographical areas or locally within the Korean Peninsula, 2) multiple colonization events throughout South and North China, Russia, Taiwan and the Korean Peninsula, and 3) recent Pleistocene expansion events from mainland founder populations. 


\section{Material and methods Fieldwork}

A total of 24 martens were collected throughout Korea and one individual from Russia (Fig. 1). All sampling was non-invasive as a consequence of road kills, with the only exception of a poached specimen (trapping) that died soon after attempted rescue, from which tissue samples were taken post mortem. Locality, gender and sampling are shown in Additional file 1. Tissue samples were obtained from different body parts depending on the condition (freshness) of the carcasses. Samples represent the whole distributional range of this species in South Korea, ranging proximal to the DMZ (Demilitarized zone between South and North Korea) to central and southern localities.

\section{Molecular work}

DNA was extracted using a Qiagen DNeasy blood and tissue kit (Qiagen, Hilden, Germany) and Chelex ${ }^{\odot} 100$ following the instructions of the manufacturer. The targeted genes were the mitochondrial cytochrome $b$ (cyt $b$ ), NADH dehydrogenase subunit 2 (nd2) and the control region $(\mathrm{cr})$ fragments and nuclear growth hormone receptor $(g h r)$. These mitochondrial sequences were available from Genbank for M. flavigula from Taiwan, China and Russia [51, 54] and therefore were chosen for comparative reasons. However, such studies lacked nuclear loci and therefore the GHR locus was only used for population comparison among the Korean localities to assess levels of heterozygosity [55]. Polymorphic positions corresponding to heterozygous individuals in the nuclear locus were coded with IUPAC ambiguity codes and all sequences were phased using DnaSP v.5.10.1 [56]. The primers used are shown in Additional file 2. Markers were designed specific for $M$. flavigula. Internal markers were designed to resolve poor quality amplification of blood samples (Additional file 2). Templates were sequenced on both strands and the complementary reads were used to resolve rare, ambiguous base-calls in Sequencher v.4.9 (Gene Codes). Additionally, BLAST searches on gene fragments were conducted against GenBank and matches with high genetic affinity of $M$. flavigula were downloaded and included in the alignment to assess the overall phylogenetic position of Korean martens. Nine Genbank M. flavigula sequences from southern and eastern China, southern Russia and Taiwan were downloaded and included in the alignment (Additional file 1).

Sequences were aligned and visualized in Seaview v.4.2.11 [57] using ClustalW2 [58] default settings. We used PartitionFinder v.2 [59] to choose the optimal partitioning scheme under a greedy search [60]. Candidate outgroup species according to the literature were $M$. melamprus, M. martes, M. foina and Gulo gulo [61, 62]. However, after inspection of preliminary phylogenetic trees, the outgroups showed very high divergence with respect to the ingroup and we therefore run all analyses without an outgroup, rooting based only on the molecular clock model. Networks were built on

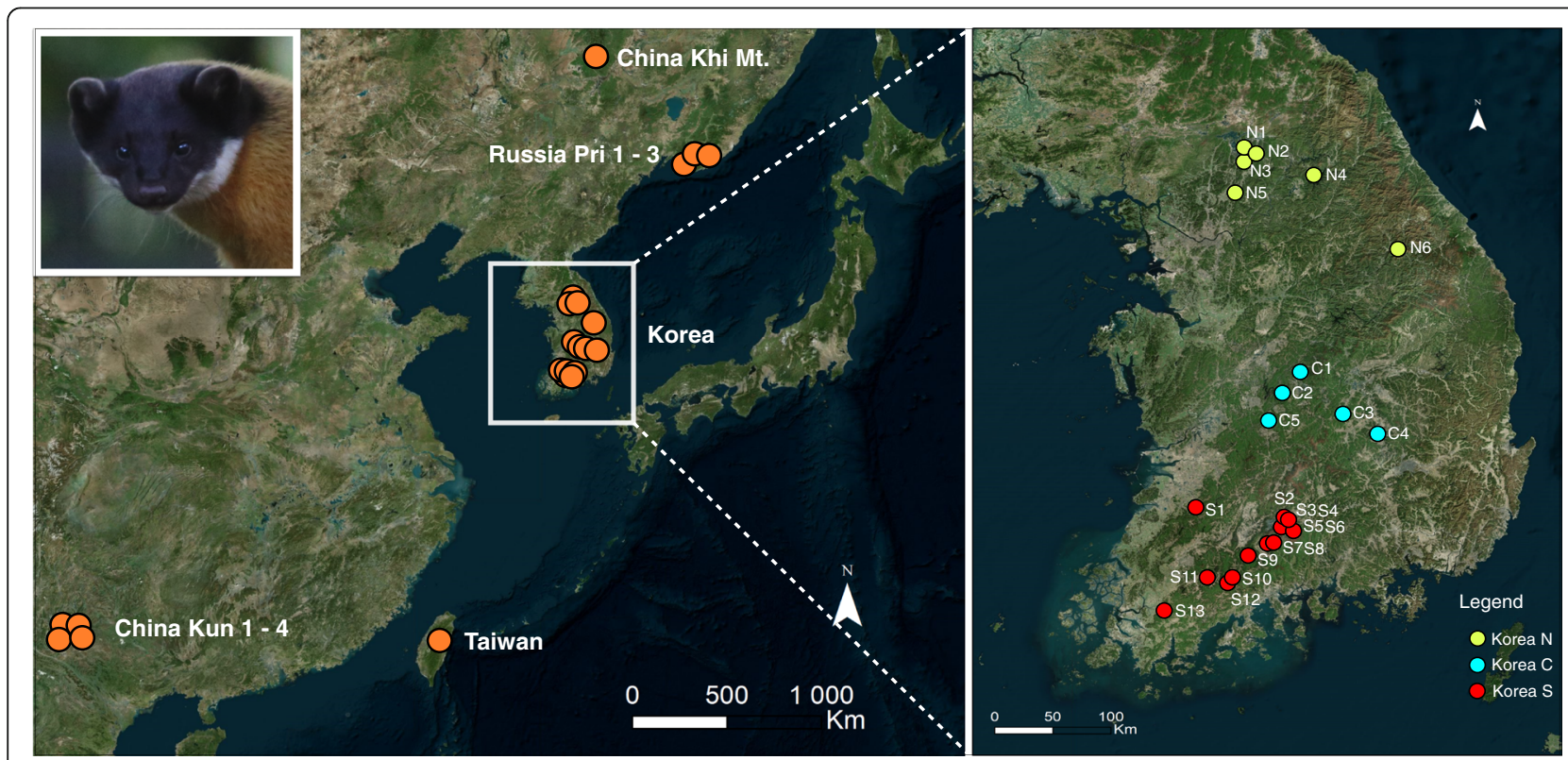

Fig. 1 Map of all Martes flavigula sampled localities used in this study. Left side of the figure shows a larger map of eastern China, Taiwan, southern Russia, the Korean Peninsula and Japan. The orange dots are samples are M. flavigula localities. The right side of the figure represents the South Korean map and the sampling sites. Sampled sites are color coded as yellow dots (northern localities), blue dots (central localities), red dots (southern localities). Photo credit of marten head picture by Donggul Woo. Map created in QGIS v.2.18.17 (Satellite image source: Bing) 
Haploviewer [63] under the best tree topology as inferred in RAxML v7.0.4 [64, 65] using default settings and a GTR model. All analyses were performed through the Cyberinfrastructure for Phylogenetic Research (CIPRES [66]).

\section{DNA sequence data}

To infer ancestry from the likely ancestral population we downloaded the only available Martes flavigula $c y t-b$ sequences in Genbank from Thailand (MFL-DUZ1 Duzit Zoo, and Genbank accession AB012362MFL-CHI1, Chiang Mai Zoo, Genbank accession AB012363). However, after careful examination, the first half of the $c y t-b$ sequence matched $M$. melampus and the second half $M$. flavigula. The change happened exactly after the internal $c y t-b$ primers employed in their study [67] and thus indicates a possible error. Unfortunately, these two sequences have been included in numerous studies on the phylogeography of Martes and therefore we suspect that the chronological phylogeographic estimates, at least in part, might be inaccurate or erroneous. Thus, only the second half of the $c y t-b(581 \mathrm{bp})$ remained usable. However, because of these issues, in addition to the unconfirmed origin (as they came from a zoo), these sequences were not included in the final analyses. Nevertheless, they were included in the MCMC (Monte Carlo Markov Chain) continuous phylogeography analysis shown in Additional file 3. One sequence of $M$. flavigula (AY882061) coming from China's Kunming zoo was included in the analyses as it matched very closely to other martens from the Kunming Province. When geographical positioning system (GPS) coordinates were not available from published records, we used the center GPS coordinate for their alleged location.

\section{Bayesian coalescent and phylogeographic analyses}

First, we performed statistical coalescent and phylogeographic analyses using BEAST v1.8.3 ([68]; http://beast.bio.ed.ac.uk). We inferred a mitochondrial gene tree based on a constant coalescent model, by linking all mitochondrial partitions (as they represent the same locus), but specifying separate nucleotide substitution and molecular clock models; HKY + G and strict clock for each, respectively. In order to time-calibrate the population tree, we fixed the mutation rate in $c y t-b$ to $2.403 \times 10^{-8}$ substitutions/site/year following [69]. For the population size parameter, we used a prior lognormal distribution (in real space) with mean $=70,000$ (based on a preliminary run using uninformative priors) and standard deviation $=0.5$. For the prior distributions in the clock rates of $n d 2$ and $c r$ we selected a diffuse gamma distribution (shape $=1$, scale $=1 \times 10^{-8}$ ). In addition to the gene tree, we co-estimated the dispersal history using a discrete phylogeographic (ancestral state reconstruction) model also implemented in
BEAST [70]. Given that our geographic sampling of populations is uneven and our state-space is low, we chose an asymmetric continuous-time rate matrix with $\left(n^{2}\right)-n$ transition-state parameters (where $n$ is the number of location or states) [71]. This model assumes an asymmetric transition rate between any two states. As priors for the rates, we selected the approximate reference prior, which is specific for continuous-time Markov chain (CTMC) [72].

Secondly, we inferred changes in effective population size through time using a Bayesian Skyline Plot (BSP) model [73] with a strict clock for the $c y t-b$ data and the same prior clock for the $n d 2$ and $c r$ fragments. For both analyses, we ran two independent MCMC chains, each with 20 million states and sampling every 4000th state. Independent runs were evaluated for convergence and mixing by observing and comparing traces of each statistic and parameter in Tracer v1.6 ([74] http://beast.bio.ed.ac.uk/tracer). We considered effective sampling size (ESS) values $>200$ to be good indicators of parameter mixing. The first 500 states of each run were discarded as burnin, and samples were merged using LogCombiner v1.8.3. The resulting 9000 states were summarized using TreeAnnotator v1.8.3, where a maximum-clade-credibility (MCC) tree with mean values were generated under the "-heights ca" option [75].

Thirdly, to estimate M. flavigula population range changes through time and ancestral population location or origin, we employed a diffusion approach of the mitochondrial sequence data through time using a continuous Bayesian phylogeographic approach [76]. We used the Cauchy (Random Walk, RRW hereafter) model with all individuals assigned to GPS coordinates with a random "jitter" with a window size of 0.5. We applied a fixed clock rate to the $c y t-b$ data set and estimated rates from the prior for $n d 2$ and $c r$. To select for the continuous trait model we used marginal likelihood estimations (MLE) and Bayes factors (BF). MLE were calculated with path sampling (PS) and stepping stone (SS) analyses in BEAST [77] (Additional file 4). We tested for Brownian, Cauchy, Gamma and Lognormal RRW models under the strict clock models running 100 million generations, sampling every 10,000 generations. Gamma RRW ESS were low $(<50)$ and therefore were not estimated. For all the models tested, MLE analyses were run for 50 path steps and 100,000 generations with each step. The BF were calculated as twice the difference in MLE between alternative models, and the significance was determined if the BF value was $>10$ [78]. SPREAD [79] was used to compute spatial continuous space MCC trees and viewed in Google Earth (http://earth.google.com).

Biogeographical reconstructions were performed using the statistical dispersal-vicariance analysis (S-DIVA) method [80] as implemented in RASP 2.1 [81, 82]. We used all the post-burnin trees and the MCC tree from 
the concatenated BEAST analyses as input of the S-DIVA analysis, sampling 1000 trees randomly. We defined 5 areas as (a) Korea; (b) Russia, (c) East China, (d) Taiwan, and (e) South China.

Tajima's D [83], Fu's Fs [84] and a mismatch distribution analysis [85] were estimated to examine signs of historical population expansions. Negative values of Tajima's D and Fs can be interpreted as evidence of population expansions, and as an excess of recent mutations and reject population stasis, respectively. A diagram of frequencies of pairwise genetic differences were drawn using DnaSP v.5.10.1 [56]. One thousand bootstrap replicates were used to generate an expected distribution using a model of sudden demographic expansion [86]. Mismatch distributions are often unimodal in populations following recent population demographic and range expansion but are multimodal in samples drawn from populations at demographic equilibrium [85-88]. Based on the lack of differentiation between regions (Korean, Chinese, Russian, and Taiwanese populations), all data was considered as one population for demographic analyses.

\section{Results}

\section{Alignments and markers}

The nuclear GHR gene fragment had the lowest genetic polymorphism, with only one polymorphic site (haplotype diversity: $\mathrm{Hd}=0.294$, Nucleotide diversity per site, $\mathrm{Pi}=$ $0.00066)$, with 6 heterozygotes $C$ or $T(n=1$; North population, $n=2$; center population; 3 ; South population), and 17 homozygotes, $(\mathrm{n}=1, \mathrm{~T}$; and $n=16, \mathrm{C})$. The lengths of the alignments were: 993 bp (cyt-b), 957 bp (nd2), 592 (cr) and $443(g h r)$. The combined mitochondrial data set resulted in $2542 \mathrm{bp}$. For the concatenated mitochondrial data set, a total of 9 haplotypes were recovered, 5 of these from the Korean Peninsula. The $g h r$ alignment recovered 2 haplotypes from the Korean Peninsula. The best partition schemes inferred by PartitionFinder, employed for the Maximum Likelihood (ML) network in Haploviewer, were: 1) $c y t-b+n d 2$ 1st codon position, $c y t-b+n d 2$ 2nd codon position, $c y t-b$ 3rd codon position $+c r$, $n d 23$ rd codon position. The $g h r$ network was run under no partition scheme.

\section{Genealogy, dispersal history and demography}

Runs showed high Effective Sample Size ( $>200)$, indicating adequate sampling of the posterior distribution. Both discrete and continuous MCC trees (Fig. 2), based on mitochondrial data, recovered highly similar topologies with the former showing stronger node support for the tree tips and the latter for deeper nodes. Timings were reported only from the continuous MCC tree (Additional file 5) (based on GPS coordinates) and not from the discrete analysis that relies on assigned localities (e.g., Russia vs eastern China) and can be partially subjective. The time to the most recent common ancestor (TMRCA) for these populations was estimated to be 107 kya (mean height, range 178-55 kya HPD; Highest Posterior Density) based on the continuous concatenated mitochondrial genealogy. The Korean Peninsula population was paraphyletic, and recovered two clades. The Korean Peninsula+South China clade dated ca. 50 kya (HPD; 89-19 kya) and within this clade a younger Korean clade dated 15 kya (HPD; 33-4 kya). The larger clade recovered Taiwanese, Russian, East Chinese and Korean populations. Within this clade, the Taiwanese population was sister to all other populations (63 kya, HPD; 108-28). Here, two sister clades (TMRCA; 30 kya, HPD; 55-11) were recovered, an older clade (Korean+Russian, 22 kya, HPD; 41-8) and a younger clade (Korean+Russian+East Russia, 12 kya, HPD; 27-3). The continuous MCC ancestral root (125 kya) resulted equidistant between southern China and the Korean Peninsula. Two colonization events commence at this time, one towards the West (eastern China) and a second towards the East (Korean Peninsula). The eastern lineage follows a further northern (towards the Korean Peninsula) and southern (towards Taiwan) branching event South of Jeju Island (South of the peninsula) ca. 80 kya.

Results suggest that the Korean Peninsula was colonized ca. 60 kya followed by Taiwan ca. 10 kya. Similarly, a second colonization event from China was inferred ca. 60 kya (Fig. 3) arriving to the peninsula ca. 20 kya. A colonization event from the Korean Peninsula towards Russia and eastern China dated to the last 10 kya (Fig. 3). The continuous cyt-b MCC tree that included neotropical M. flavigula (Additional file 3) failed to recover Thailand as ancestral to all other localities.

The greatest ancestral node uncertainty fell within older divergence estimates, as seen by weaker Bayesian posterior probabilities (Fig. 2). This was confirmed by the S-DIVA analysis that showed a limited performance to infer vicariant events in the area. Results from S-DIVA could not recover unambiguously any of the attributed assigned distribution areas as the ancestral area, as might be expected from population panmixia (Fig. 2). The highest probabilities for all nodes (a-i) were the following: node 'a' (Korea-Taiwan-South China $35 \%$ ), node 'b' (three equal origins; Korea-Taiwan-South China 17\%; Korea-Taiwan $17 \%$, Korea $17 \%$ ), node 'c' (Korea-South China 100\%), node 'd' (Korea-Taiwan, $40 \%$ ), node e' (Korea 38.5\%), node 'f' (Korea 38.5\%), node 'g' (Korea 61.8\%), node ' $h$ ' (Korea $60.5 \%$ ), node 'i' (Korea-Russia, 98.7\%). Overall the more recent divergence estimates and ancestral distributions indicated a likely Korean ancestry with diversification episodes from the Korean Peninsula into Taiwan, Russia and eastern China (Figs. 2 and 3). 


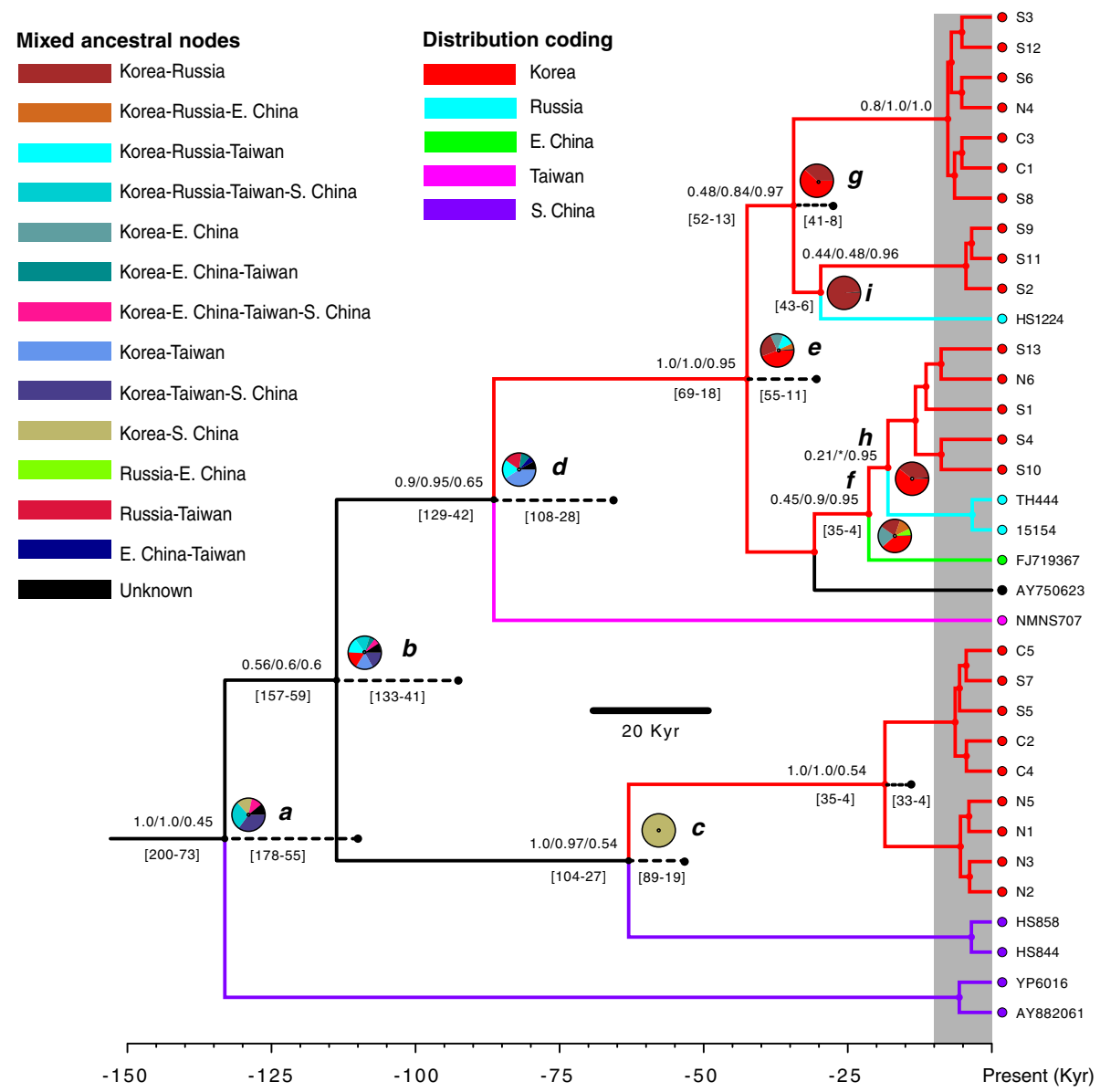

Fig. 2 Discrete coalescent tree of Martes flavigula. Node circles are color coded by localities. Values by nodes are posterior probabilities recovered from the analysis. Pie charts by nodes represent results from the S-DIVA analyses of the mixed distribution nodes. Dashed black lines represent positioning of nodes from the continuous coalescent tree. The grey background represents the Holocene period. Values by nodes are clade posterior discrete probability, clade posterior continuous probability and state posterior discrete probability. Values under nodes are height posterior density (HPD), left is discrete and right continuous

The overall trend of the BSP suggests that the effective population size has declined over the last 5000 years, remaining constant at earlier times (Fig. 4). The multimodal mismatch distribution of the Korean samples $(n=24)$, and both Korean and mainland individuals $(n=29)$ suggests population stasis (Additional file 6). Korean samples; Fu's $\mathrm{F}=8.0$ (significant $p<0.05$ ), Tajima's D $=2.29$ (significant, $\mathrm{p}<0.05$ ), SSD (sum of Square Deviations $=0.10, \quad$ significant $p=0.01), \quad$ Raggedness index $=0.29$ (significant, $p=0.001$ ) and Mainland and Korean samples; Fu's $F=3.9$ (non-significant), Tajima's $\mathrm{D}=-0.2$ (non-significant), $\mathrm{SSD}=0.06$ (significant $\mathrm{p}=$ 0.01 ), Raggedness index $=0.17$ (significant, $\mathrm{p}=0.001$ ). These results confirm the observed population decline of the BSP (Fig. 4). The ML (Maximum Likelihood) RAxML network shows a lack of population structure (within northern, central or southern Korea) and with southern, eastern China, Russia and Taiwan. Within Korea, only two areas (northern and southern Korea) recovered distinct haplotypes. All other Korean haplotypes are constituted by individuals from; 1) northern, central, southern Korea, 2) central, southern Korea and 3) southern Korea and Russia (Fig. 5).

\section{Discussion}

The topography and location of the Korean Peninsula has played a pivotal role in its colonization by many animals [7]. The repetitive connections between the Korean Peninsula and the Mainland through sea-level drops of the Yellow Sea during times of glacial maxima and the high dispersal capability of M. flavigula adds to the lack of geographical structure in this species and the paraphyly of the Korean population (Figs. 2, 3 and 5). Martes flavigula started diversifying as early as the Tarantian age (126-11.7 kya) during the Pleistocene from southern China. The ancestral root (125 kya) equidistant between the Korean Peninsula and southern China suggests at least two migrations or dispersal 


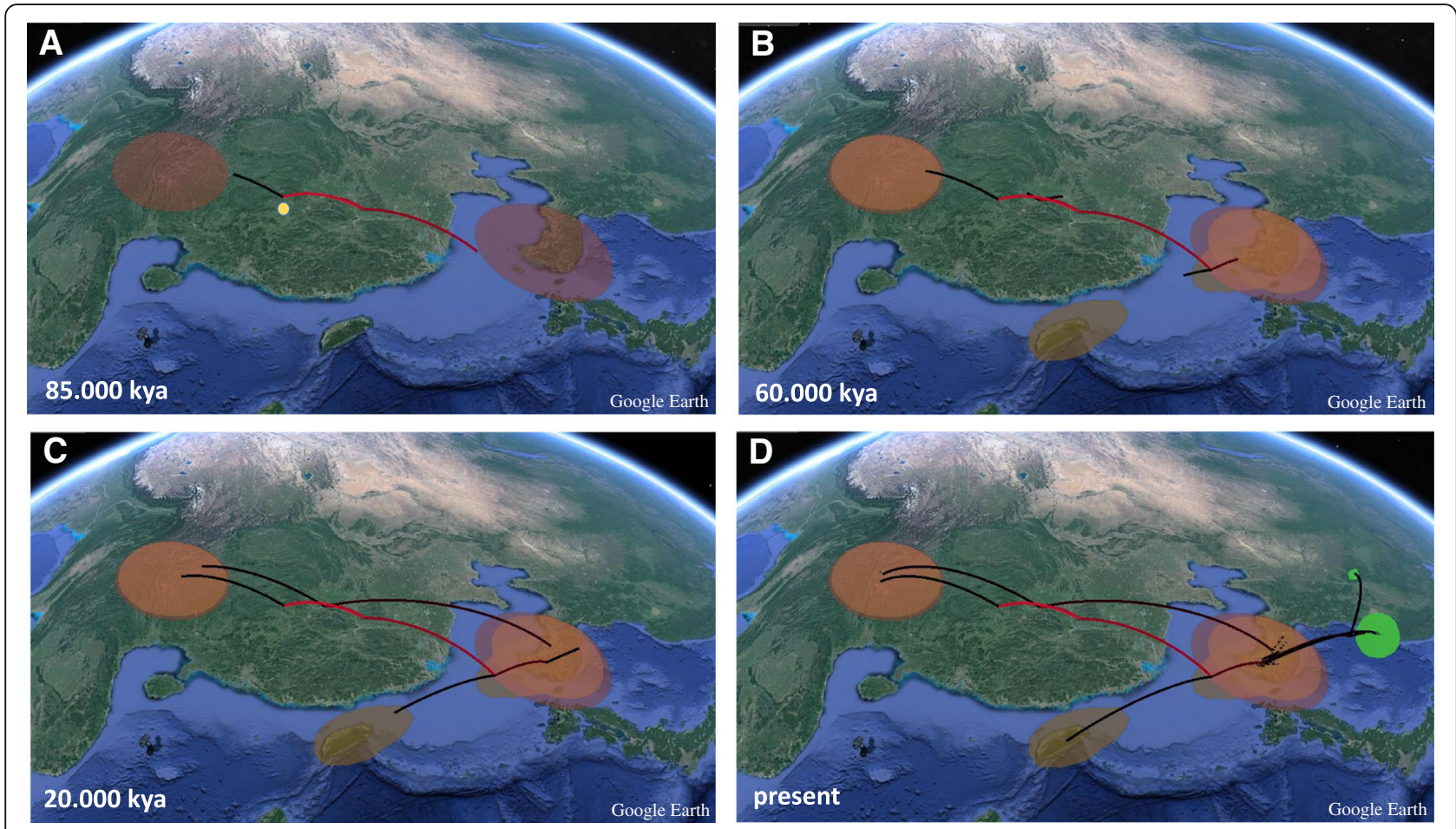

Fig. 3 Map of the area including China, Russia, Taiwan, Korean Peninsula and Japan with Bayesian phylogeographic projections of the Martes flavigula population MCC tree at different time scales. Old diffusions of the MCC branches and polygons are in red and in green are recent expansions. The yellow dot represents the origin of the studied populations. a: population expansions up to $85 \mathrm{kya}$, b: up to $60 \mathrm{kya}$, c: up to 20 kya, d: up to present time. Map from Google Earth (@2018 Google)

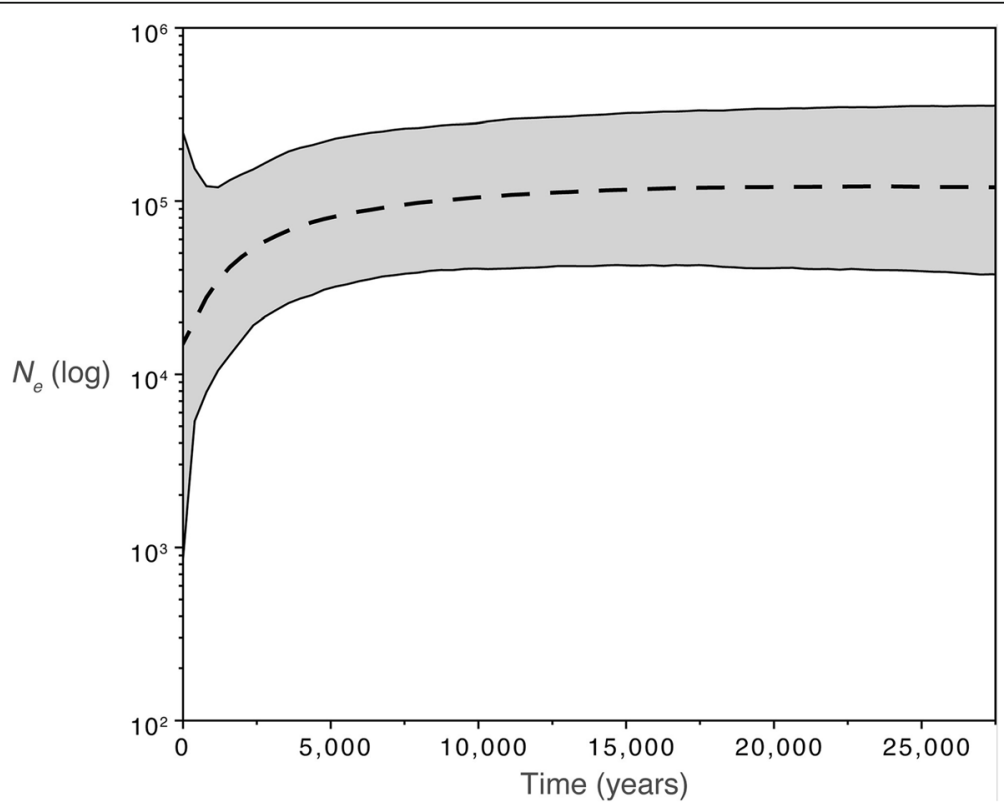

Fig. 4 Bayesian Skyline Plot of all Martes flavigula (Mainland and Korean Peninsula) used in this study for the concatenated mitochondrial data set $(c y t-b, n d 2, c r)$ 


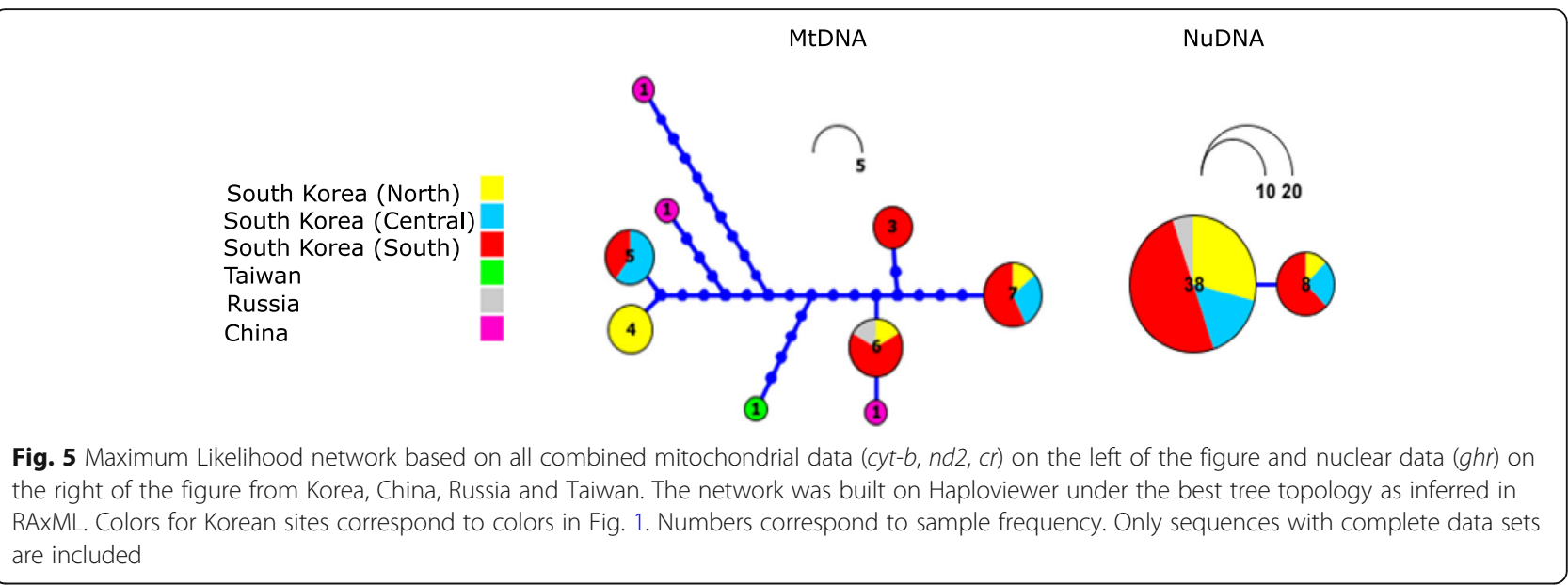

events towards the Korean Peninsula through the Yellow Sea. The first colonization event dates back to ca. 60 kya and a more recent arrival at around 20 kya. Although we cannot ascertain the origin of the Taiwanese population, the data and timing would support a possible Korean origin. It is likely that arrival at Taiwan as well as the event towards northern localities occurred recently, during the Holocene (ca. 9 kya; Figs. 2 and 3) following interglacial conditions and warmer periods.

The close phylogenetic affinity in M. flavigula from the Korean Peninsula, Russia (Primorye), East, South China (Lesser Khingan Mountains and Kumming province, respectively) and Taiwan has similarly been found in other mustelid species such as Mustela sibirica and $M u$. nivalis and concurs with a scenario of recent continental marine regression during glacial periods in the area $[24,51]$. Furthermore, our trees recover the same phylogenetic position as that of Taiwanese Mu. sibirica in relation to its counterpart populations in the Korean Peninsula, Russian and East China [24]. Four species of mustelids (including $M$. flavigula) colonized Taiwan from nearby China during the Pleistocene via land bridge connections through sea level regression at glacial periods [51]. Such colonization events support multiple episodes of migration from the Mainland, one for each species, largely in accordance with other Taiwanese fauna [89-93]. Martes flavigula's estimated time of colonization (based on fossil data calibrations) between the Mainland-Taiwanese population (110 kya, HPD 190-40) lies within our estimated time range of ancestral M. flavigula migrations, at around the Late Pleistocene [51]. The observed mixed ancestral population origins, as inferred from the biogeographic analyses (Figs. 2 and 3) may be indicative of a recent founder population towards the East.

Genotype analyses of a $M$. flavigula population $(n=21)$ at four localities in Mountain Jiri in South Korea revealed an overall low mean relatedness and moderate genetic diversity [52]. Low kinship can often be associated with higher dispersal [94], which in mammals is attributed to resource competition avoidance and reduced levels of inbreeding $[95,96]$. Furthermore, a juvenile female was reported to have moved $40 \mathrm{~km}$ before been road killed, again confirming their high dispersal capability [52]. These data concur with our expected lack of genetic structure throughout Korea and supports long distance movement of groups and mixing of nearby populations [97]. Similarly, other carnivores in the region such as the red fox (Vulpes vulpes) and the grey wolf (Canis lupus) with high dispersal mobility and high habitat adaptability [36, 37, 98], show unclear phylogeographic patterns and lack of population structure $[99,100]$. More recently, work on red foxes in Korea, China and Russia showed admixture between Chinese and Russian populations [38]. Similarly, a lack of geographical structure in Raccoon dog (Nyctereutes procyonoides) populations of the Korean Peninsula has been attributed to dispersal, changing climate and geography over the past 50 kya, preceding their population expansion after the Last Glacial Maximum [16]. Furthermore, large and medium sized mammal populations from the Korean Peninsula show high genetic affinity to those from Russia, such as is the case for the Asian black bear (Ursus thibetanus) [101], the Siberian tiger (Panthera tidris) [39] and the Eurasian badger (Meles leucurus) [34], which suggest southward migrations from eastern Asia throughout glacial times. Contrasting findings derive from small mammals with more restricted or constrained dispersal capability, such as the Korean Field mouse (Apodemus peninsulae) and the Korean red-backed vole (Myodes regulus) from Eurasia, with Korean populations distinct from Russian and/or China, and are arguably Korean endemics $[20,21]$. Other more restricted species such as the Siberian chipmunk (Tamias sibiricus) show strong genetic structure with northern, central and southern populations in South Korea [22]. A higher genetic differentiation correlates with earlier divergence times. For example, in the 
Striped field mouse (Apodemus agrarius), genetic divergences between populations in Russia, South Korea and central Asian populations range from 175 to $192 \mathrm{Kya}$, and between Taiwan and China from 450 to 500 kya [93]. Similarly, the divergence time of Chinese and Taiwanese populations in the Asian lesser white-toothed shrew (Crocidura shantungensis) dates between 192 and 397 kya. This suggests that the Korean Peninsula, Russia and Taiwan acted as refugia throughout the Pleistocene [20] for small mammals, pre-dating the arrival of $M$. flavigula to those regions.

The Yellow Sea, separating South Korea and central and northeastern China, was partly dry land throughout the last glacial period [102] and served as a land bridge between now isolated islands, and as a connective corridor at the end of the last glacial cycle [103]. Evidence of periods of connectivity by marine regression derives from recent molecular work on the Asian badger (Meles leucurus), where populations from Korea (including Jeju island in the South), East Russia, Mongolia and West Siberia showed little genetic divergence between haplotypes, indicating high population dispersal [34]. Similarly, phylogenetic work on Laxmann's shrew (Sorex caecutiens) from the Korean Peninsula show admixture with Asian populations but monophyly in Jeju Island [35]. The recovery of distinct mitochondrial lineages at different localities in Russia, Tsushima Islands and Taiwan, has been put forward as evidence of areas of refugia throughout the Pleistocene [24].

Further insights into the biogeography of M. flavigula and the timing of colonization of the Korean Peninsula can be further understood from the species distribution range and its absence in Japan, as has been shown for other species of mustelids in the region [32, 40]. Park et al. (2000) [32] argues that the shallow depths of the Korean Straight during the Last Glacial Maximum resulted in a 95\% reduction of the cross-sectional area between Japan and South Korea, but both land-masses were not recently connected $[32,103,104]$. The reasoning for the non-closure lies on the paleo-Tsushima Current flowing in this area between 25 and 15 kya [32], which did not allow ice to settle in the area North of the Tsushima Island. Thus, the last of the Pleistocene connections between the Eurasian continent and Japan dates to the Late Pleistocene $[28,88,91,105]$ and therefore suggests that these land bridges occurred long before the arrival of $M$. flavigula to the Korean Peninsula, which might have happened up to 60 kya (Figs. 2 and 3). Molecular studies date such colonization events of mammals to up to 150 kya [24-28]. The Japanese weasel (Mustela itatsi) and the Sika deer (Cervus nippon) are some examples of mammals not found but that crossed over from the Peninsula to Japan before the sea started to rise $[24,28]$. Thus, the presence of $M$. flavigula in Korea, in the mainland and Taiwan and absence in the Japanese islands follows patterns of topographic changes by Pleistocene climatic conditions. Similarly, successive dispersal events from the mainland to the Korean Peninsula postdate such events, as do the probable outward dispersal events from the peninsula to Taiwan (between 60 and 20 kya) and northern localities at the turn of the LGM. These data agree with LGM (ca. 23.5-18 kya) connections throughout the area, coastal China, Korea and Taiwan [14, 31]. Evidence of dispersal events derives from the lack of genetic divergence in Mustela sibirica mtDNA sequences between Korea and the Tsushima Islands (between South Korea and Japan) and Jeju Island, suggesting a recent land bridge connection in the area [54, 106, 107]. Similarly, the leopard cat (P. bengalensis) in Tsushima Islands shows close genetic affinity to the mainland and is not present in Japan [107]. Although the divergence time estimates do suggest that $M$. flavigula was already present in the Korean Peninsula at the time of the LGM sea regression, its presence in Jeju Island and Tsushima Islands has not been reported.

The causes and effects behind M. flavigula's observed population decline (Fig. 4) are difficult to assess but likely reflect a combination of factors such as indirect anthropogenic impacts (e.g., through habitat disturbance and or the introduction of domestic species) and past climatic changes in the area $[108,109]$. The start of $M$. flavigula's population decline ca. 10 kya coincides with marine transgression throughout the interglacial period ( 13-7.5 kya, [8]) and could indicate the loss of genetic diversity through northern population expansions to the mainland when new habitat became available. In addition, the more accentuated decline within the last 3 kya (Fig. 4) coincides with the first appearance of rice fields in the Korean Peninsula, which severely altered the environment through the building of rice paddies $[110,111]$.

\section{Conclusion}

Here, we report on the biogeography of the yellowthroated marten from South Korean populations, Taiwan, southern and eastern China and eastern Russia. We find a recent population origin throughout its geographical range with at least two Pleistocene expansions towards the Korean Peninsula from central China. Such colonization events are likely a consequence of the proximity, topography and geography of the Korean Peninsula. The repetitive land connections between the Korean Peninsula and the Mainland through sea-level falls of the Yellow Sea at times of glacial maxima and the high dispersal capability of M. flavigula adds to the lack of geographical structure in this species and the paraphyly of the Korean population. In general, 
insufficient population sampling typically leads to a false signal of population structure. In contrast and in spite of our sample size, we do not observe structured populations, but rather a signal of high dispersal capability. These findings may be further assessed in studies with broader sample sizes and denser genetic markers.

\section{Additional files}

\section{Additional file 1: Martes flavigula codes, country of origin and sampling. (DOCX $14 \mathrm{~kb}$ )}

Additional file 2: Primers use to amplify Martes flavigula gene fragments. (DOCX $12 \mathrm{~kb}$ )

Additional file 3: Continuous coalescent tree of Martes flavigula including the two short (581 bp) cyt-b fragments from Thailand. High posterior probability nodes are represented in red circles. Thailand is highlighted in red and South China in green. (DOCX $115 \mathrm{~kb}$ )

Additional file 4: Marginal likelihood estimates and Bayes factor comparison of coalescent priors for Martes flavigula. The asterisk $\left(^{*}\right.$ represents the best model selected. (DOCX $12 \mathrm{~kb}$ )

Additional file 5: Continuous coalescent tree of Martes flavigula. Posterior probability nodes are represented in red circles. (DOCX 96 kb)

Additional file 6: Mismatch distribution analyses of A) $c y t-b, B$ ) nd2, C) cr for all Martes flavigula individuals. (DOCX $25 \mathrm{~kb}$ )

\section{Abbreviations}

BF: Bayes factors; bp: base pairs; BP: Before present; ca: circa; CIPRES: Cyberinfrastructure for Phylogenetic Research; cr: Control Region; CTMC: Continuous-time Markov chain; cyt-b: Cytochrome b; DMS: Korean Demilitarized Zone; ghr: Growth Hormone Receptor; GPS: Geographical positioning system; HPD: Height Posterior Density; kya: thousand years ago; LGM: Last Glacial Maxima; MCC: Monte Carlo Chain; MLE: Marginal Likelihood Estimations; nd2: NADH dehydrogenase subunit 2; PS: Path sampling; RRW: Repeated Random walk; S-DIVA: Statistical dispersal-vicariance analysis; SS: Stepping stone; SSD: Sum of Square Deviations; TMRCA: Time to the Most Recent Common Ancestor

\section{Acknowledgements}

We are thankful to the Conservation Genome Resource Bank for Korean Wildlife (CGRB). We thank Dr. Christopher Blair for comments on the manuscript prior to publication. We thank Salvador Arenas-Castro for support with QGIS.

\section{Funding}

This study was funded by an International collaborative grant to MJJ by the National Institute of Ecology (South Korea). This grant funding covered the wages for MJJ and all molecular expenses involved for this study. Fieldwork and surveys were funded by the South Korean Ministry of Environment to ES DW and TC.

\section{Availability of data and materials}

All data regarding this article will be included as Genbank accessions MK205189-MK205286 at https://www.ncbi.nlm.nih.gov/genbank/.

\section{Authors' contributions}

MJJ and DW conceived and initiated the project in coordination with all the authors. ES DW TC IV conducted all the fieldwork and surveyed the Korean Peninsula and Southern Russia to locate all M. flavigula sites and supplied all samples. MJJ performed the laboratory experiments. MJJ analyzed the data with input from SSR. MJJ wrote the first draft manuscript with contributions from SA and SSR. MJJ SSR and SA interpreted the data. ES DW TC IV contributed to the discussion and interpretation of the distribution and topography of the region and ecology of the species. All the authors read and approved the final manuscript.

\section{Ethics approval and consent to participate}

The samples consisted of tissues from dead carcasses and therefore no alive Martens were handled for the purpose of this study. This study was approved by the South Korean Environmental authorities. Sampling procedures were issued as part of the application for permits for the fieldwork, which did not affect any endangered or protected species. Permits were granted by the South Korean Ministry of Environment (Permit numbers for tissue collections: 2016-46, $15,16,2017-03,01,05)$. All sampling complies with institutional (National Institute of Ecology) and national (South Korea) guidelines.

\section{Consent for publication}

Not applicable.

\section{Competing interests}

The authors declare that there are no competing interests.

\section{Publisher's Note}

Springer Nature remains neutral with regard to jurisdictional claims in published maps and institutional affiliations.

\section{Author details}

${ }^{1} \mathrm{CIBIO} / \mathrm{InBIO}$ (Centro de Investigação em Biodiversidade e Recursos Genéticos), Universidade do Porto, Campus Agrario De Vairão, 4485-661 Vairão, Portugal. ${ }^{2}$ National Institute of Ecology, 1210, Geumgang-ro, Maseo-myeon, Seocheon-gun, South Chungcheong province 33657, Republic of Korea. ${ }^{3}$ Department of Ecology and Evolutionary Biology, University of Toronto, 25 Willcocks, Toronto, Ontario M5S 3B2, Canada. ${ }^{4}$ Institute of Evolutionary Biology and Environmental Studies (IEU), University of Zurich, Winterthurerstrasse, 190 Zurich, Switzerland. ${ }^{5}$ United Administration of Lazovsky State Nature Reserve and National Park "Zov tigra", 56 Centralnaya St. Lazo, Primorsky Krai 692980, Russia.

Received: 16 October 2018 Accepted: 2 January 2019

Published online: 14 January 2019

\section{References}

1. Hewitt G. The genetic legacy of the quaternary ice ages. Nature. 2000;405: 907-13.

2. Knowles LL. Did the Pleistocene glaciations promote divergence? Tests of explicit refugial models in montane grasshopprers. Mol Ecol. 2001;10:691-701.

3. Veith M, Kosuch J, Vences M. Climatic oscillations triggered post-Messinian speciation of Western Palearctic brown frogs (Amphibia, Ranidae). Mol Phyl Evo. 2003;26:310-27

4. Avise JC. Twenty-five key evolutionary insights from the phylogeographic revolution in population genetics. In: Weiss S, Ferrand N, editors. Phylogeography of Southern European Refugia. Dordrecht: Springer; 2007. p. 7-21.

5. Gavin DG, Fitzpatrick MC, Gugger PF, Heath KD, Rodríguez-Sánchez F, Dobrowski SZ, Hampe A, Hu FS, Ashcroft MB, Bartlein PJ, Blois JL, Carstens $B C$, Davis EB, de Lafontaine G, Edwards ME, Fernandez M, Henne PD, Herring EM, Holden ZA, Kong W-S, Liu J, Magri D, Matzke NJ, McGlone MS, Saltré F, Stigall AL, Tsai Y-HE, Williams JW. Climate refugia: joint inference from fossil records, species distribution models and phylogeography. New Phytol. 2014;204:37-54.

6. Hewitt GM. Genetic consequences of climatic oscillations in the quaternary. Philos Trans R Soc Lond Ser B Biol Sci. 2004:359:183-95.

7. Borzée A, Santos JL, Sánchez-Ramirez S, Bae Y, Heo K, Jang Y, Jowers MJ. Phylogeographic and population insights of the Asian common toad (Bufo gargarizans) in Korea and China: population isolation and expansions as response to the ice ages. PeerJ. 2017:5:e4044 https://doi.org/10.7717/peerj.4044.

8. Kim J-M, Kennett JP. Paleoenvironmental changes associated with the Holocene marine transgression, Yellow Sea (Hwanghae). Mar Micropaleontol. 1998;34:71-89.

9. Li J, Hu BQ, Wei HL, Zhao JT, Zou L, Bai FL, Dou YG, Wang LB, Fang XS. Provenance variations in the Holocene deposits from the southern Yellow Sea: clay mineralogy evidence. Cont Shelf Res. 2014;90:41-51.

10. Yi S, Saito Y, Oshima H, Zhou Y, Wei H. Holocene environmental history inferred from pollen assemblages in the Huanghae (Yellow River) delta, China: climatic change and human impact. Quat Sci Rev. 2003;22:609-28.

11. Kong GS, Park SC, Han HC, Chang JH, Mackensen A. Late Quaternary paleoenvironmental changes in the southeastern Yellow Sea, Korea. Quarter Int. 2006;144:38-52. 
12. Kim JC, Eum CH, Yi S, Kim JY, Hong SS, Lee JY. Optically stimulated luminescence dating of coastal sediments from southwestern Korea. Quat Geochronol. 2012;10:218-23.

13. Wepfer PH, Guenard B, Economo EP. Influences of climate and historical land connectivity on ant beta diversity in East Asia. J Biogeogr. 2016;43:2311-21.

14. Ota H. Geographic patterns of endemism and speciation in amphibians and reptiles of the Ryukyu archipelago, Japan, with special reference to their paleogeographical implications. Res Popul Ecol. 1998;40:189-204.

15. Aizawa M, Kim Z-S, Yoshimaru H. Phylogeography of the Korean pine (Pinus koraiensis) in northeast Asia: inferences from organelle gene sequences. J Plant Res. 2012;125:713-23.

16. Kim SI, Park SK, Lee H, Oshida T, Kimura J, Kim YJ, Nguyen ST, Sashika M, Min MS. Phylogeography of Korean raccoon dogs: implications of peripheral isolation of a forest mammal in East Asia. J Zool. 2013;290:225-35.

17. Park Y, Khim B, Zhao S. Sea level fluctuation in the Yellow Sea Basin. J Korean Soc Oceanograp. 1994;29:42-9.

18. ljiri A, Wang L, Oba T, Kawahata H, Huang C-Y, Huang C-Y. Paleo environmental changes in the northern area of the East China Sea during the past 42,000 years. Palaeogeography. 2005;219:239-61.

19. Mayr E. Change of genetic environment and evolution. In: Huxley J, Hardy AC, Ford EB, editors. Evolution as a Process. London: Unwin Brothers; 1954. p. $157-80$

20. Serizawa K, Suzuki H, Iwasa MA, Tsuchiya K, Pavlenko MV, Kartavtseva IV, Chelomina GN, Dokuchaev NE, Han SH. A spatial aspect on mitochondrial DNA genealogy in Apodemus peninsulae from East Asia. Biochem Genet. 2002:40:6149-61.

21. Koh HS, Yang BK, Heo SW, Jang KH, In ST. Genetic distinctiveness of the Korean red-backed vole (Myodes regulus) from Korea, revealed by mitochondrial cytochrome b gene sequences. Biochem Genet. 2011;49:153-60.

22. Lee MY, Lissovsky AA, Park SK, Obolenskaya EV, Dokuchaev NE, Zhang YP, Yu L, Kim YJ, Voloshina I, Myslenkov A, Choi TY, Min MS, Lee H. Mitochondrial cytochrome b sequence variations and population structure of Siberian chipmunk (Tamias sibiricus) in northeastern Asia and population substructure in South Korea. Mol Cells. 2008:26:566-75.

23. Lee S-J, Lee M-Y, Lin L-K, Lin K, Yuchun Li Y, E-Hyun Shin E-H, Han S-H, Mi M-S, Lee H, Kim KS. Phylogeography of the Asian lesser white-toothed shrew, Crocidura shantungensis, in East Asia: role of the Korean peninsula as refugium for small mammals. Genetica. 2018;146:211.

24. Masuda R, Kurose N, Watanabe S, Abramov AV, Han S-H, Lin L-K, Oshida T. Molecular phylogeography of the Japanese weasel, Mustela itatsi (Carnivora: Mustelidae), endemic to the Japanese islands, revealed by mitochondrial DNA analysis (2012). Biol J Linn Soc. 2012;107:307-21.

25. Ohshima K. The history of straits around the Japanese islands in the LateQuaternary. Quat Res. 2012;29:193-208 (in Japanese with English abstract).

26. Ohshima K. The Late-Quaternary Sea-level change of the Japanese Islands. J Geogr. 1991;100:967-75 (in Japanese).

27. Oshida K. The history of strait formations around the Japanese islands. Kaiyou Monthly. 2000;37:208-2013 (In Japanese).

28. Nagata J, Masuda R, Tamate HB, Hamazaki S, Ochiai K, Asada M, Tatsuzawa S, Suda K, Tado H, Yoshida MC. Two genetically distinct lineages of the sika deer, Cervus nippon, in Japanese islands: comparison of mitochondrial Dloop region sequences. Mol Phyl Evo. 1999;13:511-9.

29. Lee M-Y, Lee S-M Song E, An JH, Voloshina I, Chong JR, Johnson WE, Min $M-S$, Lee $H$. Phylogenetic relationships and genetic diversity of badgers from the Korean peninsula: implications for the taxonomic status of the Korean badger. Biochem Syst Eco. 2016;69:18-26.

30. Xu X, Oda M. Surface-water evolution of the eastern East China Sea during the last 36,000 years. Mar Geol. 1999;156:285-304.

31. Gao Y-D, Zhang Y, Xin-Fen Gao X-F, Zhu ZM. Pleistocene glaciations, demographic expansion and subsequent isolation promoted morphological heterogeneity: A phylogeographic study of the alpine Rosa sericea complex (Rosaceae). Sci Rep. 2015;5:11698.

32. Park S-C, Yoo D-G, Lee CW, Lee El. Last glacial sea-level changes and paleogeography of the Korea (Tsushima) strait. Geo-Mar Lett. 2000;20:64-71.

33. Lim J, Lee J-Y, Kim J-C, Hong S-S, Yang D-Y. Holocene environmental change at the southern coast of Korea based on organic carbon isotope (d13C) and C/S ratios. Quater Int. 2015;384:160-8.

34. Koh HS, Kryukov A, Oh JG, Bayarkhagva D, Yang BG, Ahn NH, Bazarsad D. Two sympatric phylogroups of the Asian badger Meles leucurus (Carnivora: Mammalia) identified by mitochondrial DNA cytochrome b gene sequences. Russ J Theriol. 2014;13:1-8.
35. Ohdachi SD, Hisashi A, Sang-Hoon H. Phylogenetical positions of Sorex sp. (Insectivora, Mammalia) from Cheju Island and S. caecutiens from the Korean peninsula, inferred from mitochondrial cytochrome $b$ gene sequences. Zool Sci. 2003;20:91-5.

36. Mech LD. Age, season, distance, direction, and social aspects of wolf dispersal from a Minnesota pack. In: Chepko-Sade BD, Halpin ZT, editors. Mammalian dispersal patterns: the effects of social structure on population genetics. Chicago: University of Chicago Press; 1987. p. 55-74.

37. Uraguchi K. Epidemiology and ecology of the red fox. In: Takatsuki N, Yamagiwa J, editors. Mammalogy in Japan 2. Tokyo: University of Tokyo Press; 2008. p. 149-71.

38. Yu J-N, Han S-H, Kim B-H, Kryukov AP, Kim S, Lee B-Y, Kwak M. Insights into Korean red fox (Vulpes vulpes) based on mitochondrial cytochrome $b$ sequence variation in East Asia. Zool Sci. 2012;29:753-60.

39. Lee M-Y, Hyun JY, Lee S-J, An J, Lee E, Min M-S, Kimura J, Kawada S-I, Kurihara N, Luo S-J, O'Brien SJ, Johnson WE, Lee H. Subspecific Status of the Korean Tiger Inferred by Ancient DNA Analysis. Anim Syst Evol Divers. 2012; 28:48-5.

40. Sato JJ. Phylogeographic and feeding ecological effects on the mustelid faunal assemblages in Japan. Anim Syst Evol Divers. 2003;29:99-114.

41. Ishida K, Sato JJ, Kinoshita G, Hosoda T, Kryukov AP, Suzuki H. Evolutionary history of the sable (Martes zibellina brachyuran) on Hokkaido inferred from mitochondrial Cytb and nuclear Mc1r and Tcf25 gene sequences. Acta Theriol. 2013;58:13-24.

42. Roberts TJ. The mammals of Pakistan. Oxford: Oxford University Press; 1997.

43. Sathyakumar S. Mustelids and viverrids of the northwestern and western Himalayas. ENVIS Bull Wild Prot Areas. 1999;2:39-42.

44. Grassman L, Tewes M, Silvy N. Ranging, habitat use and activity patterns of Binturong Arctictis binturong and yellow-throated marten Martes flavigula in north-Central Thailand. Wildlife Biol. 2005:11:49-57.

45. Zhou Y, Slade E, Newman C, Wang XM, Zhang SY. Frugivory and seed dispersal by the yellow-throated Marten, Martes flavigula, in a subtropical forest of China. J Trop Eco. 2008;24:219-23.

46. Proulx G, Aubry KB. The "Martes complex"-- an opportunity to bring together marten, fisher, sable, wolverine, and tayra biologists. CWBM. 2014;3:30-3.

47. Karanth KP. Evolution of disjunct distributions among wet-zone species of the Indian subcontinent: testing various hypotheses using phylogenetic approach. Curr Sci. 2003:85:1276-83.

48. Aubry KB, Zielinski WJ, Raphael MG, Proulx G, Buskirk SW. Biology and conservation of martens, sables, and fishers: a new synthesis. Ithaca: Cornell University Pres; 2012. p. 1-536.

49. Harrison DJ, Fuller AK, Proulx G. Martens and fishers (Martes) in humanaltered environments: An international perspective. New York: Springer Publishers; 2004

50. Parr JWK, Duckworth JW. Notes on diet, habituation and sociality of yellowthroated marten Martes flavigula. Small Car Con. 2007;36:27-9.

51. Hosoda T, Sato JJ, Lin L-K, Chen Y-J, Harada M, Suzuki H. Phylogenetic history of mustelid fauna in Taiwan inferred from mitochondrial genetic loci. Can J Zool. 2011:89:559-69.

52. Song E. Social structure based on genetic relatedness if yellow-throated martens (Martes flavigula) inferred from microsatellite loci analyses. MSC thesis. South Korea: Seoul National University; 2016.

53. Lee S, Lee S, Song W, Lee M-J. Habitat potential mapping of Marten (Martes flavigula) and leopard cat (Prionailurus bengalensis) in South Korea using artificial neural network machine learning. Appl Sci. 2017:7:912. https://doi. org/10.3390/app7090912.

54. Hosoda T, Suzuki H, Harada M, Tsuchiya K, Han S-H, Zhang Y-P, Kryukov AP, Lin L-K. Evolutionary trends of the mitochondrial lineage differentiation in species of genera Martes and Mustela. Genes Genet Syst. 2000;75:259-67.

55. Sato JJ, Yasuda SP, Hosoda T. Genetic diversity of the Japanese Marten (Martes melampus) and its implications for the conservation unit. Zool Science. 2009:26:457-66.

56. Rozas J, Sánchez-DelBarrio JC, Messeguer X, Rozas R. DnaSP, DNA polymorphism analyses by the coalescent and other methods. Bioinformatics. 2003;19:2496-7

57. Gouy M, Guindon S, Gascuel O. SeaView version 4: a multiplatform graphical user interface for sequence alignment and phylogenetic tree building. Mol Bio Evo. 2010;27:221-4.

58. Larkin MA, Blackshields G, Brown N, Chenna R, McGettigan PA, McWilliam H, Valentin F, Wallace IM, Wilm A, Lopez R. Clustal W and Clustal X version 2.0. Bioinformatics. 2007;23:2947-8. 
59. Lanfear R, Frandsen P, Wright AM, Senfeld T, Calcott B. PartitionFinder 2: new methods for selecting partitioned models of evolution for molecular and morphological phylogenetic analyses. Mol Biol Evo. 2017;34:772-3.

60. Lanfear R, Calcott B, Simon YW, Guindon S. PartitionFinder: combined selection of partitioning schemes and substitution models for phylogenetic analyses. Mol Phyl Evo. 2012;28:1695-701.

61. Kopli K-P, Deere KA, Slater GJ, Begg C, Begg K, Grassman L, Lucherini M, Veron G, Wayne RK. Multigene phylogeny of the Mustelidae: resolving relationships, tempo and biogeographic history of a mammalian adaptive radiation. BMC boil. 2008;6:10.

62. Sato JJ, Wolsan M, Prevosti FJ, D'Elia G, Begg C, Begg K, Hosoda T, Campbell $\mathrm{KL}$, Suzuki H. Evolutionary and biogeographic history of weasel-like carnivorans (Musteloidea). Mol Phyl Evol. 2012;63:745-57.

63. Salzburger W, Ewing GB, Von Haeseler A. The performance of phylogenetic algorithms in estimating haplotype genealogies with migration. Mol Eco. 2011;20:1952-63

64. Silvestro D, Michalak I. raxmIGUI: a graphical front-end for RAxML. Organ Diver Evo. 2012;12:335-7.

65. Stamatakis A. RAxML version 8: a tool for phylogenetic analysis and postanalysis of large phylogenies. Bioinformatics. 2014;30:1312-3.

66. Miller MA, Pfeiffer W, Schwartz T, Creating the CIPRES Science Gateway for inference of large phylogenetic trees. GCE. 2010. IEEE.1-8.

67. Kurose N, Abramov AV, Masuda R. Intrageneric diversity of the cytochrome b gene and phylogeny of Eurasian species of the genus Mustela (Mustelidae, Carnivora). Zool Sci. 2000;17:673-9.

68. Drummond AJ, Suchard MA, Xie D, Rambaut A. Bayesian phylogenetics with BEAUti and the BEAST 1.7. Mol Bio Evo. 2012;29:1969-73.

69. Malyarchuk B, Derenko M, Denisova G. A mitogenomic phylogeny and genetic history of sable (Martes zibellina). Gene. 2014;550:56-67.

70. Lemey P, Rambaut A, Drummond AJ, Suchard MA. Bayesian Phylogeography Finds Its Roots. PLos One. 2009. https://doi.org/10.1371/ journal.pcbi.1000520. Accessed Sept 2018.

71. O'Meara BC. Evolutionary Inferences from Phylogenies: A Review of Methods. Annu Rev Ecol Evol Syst. 2012;43:267-85.

72. Ferreira MAR, Suchard MA. Bayesian analysis of elapsed times in continuoustime Markov chains. Can J Stat. 2008:36:355-68.

73. Drummond AJ, Rambaut A, Shapiro B, Pybus OG. Bayesian coalescent inference of past population dynamics from molecular sequences. Mol Biol Evo. 2005;22:1185-92.

74. Rambaut A, Drummond AJ. Tracer ver. 1.4. 2007. Program available at http:// beast.bio.ed.ac.uk/tracer.

75. Heled J, Bouckaert R. Looking for trees in the forest: summary tree from posterior samples. BMC Evo Bio. 2013;13:221.

76. Lemey P, Rambaut A, Welch JJ, Suchard MA. Phylogeography takes a relaxed random walk in continuous space and time. Mol Bio Evo. 2010; 27:1877-85.

77. Baele G, Lemey P, Bedford T, Rambaut A, Suchard MA, Alekseyenko AV. Improving the accuracy of demographic and molecular clock model comparison while accommodating phylogenetic uncertainty. Mol Bio Evo. 2012;29:2157-67.

78. Kass RE, Raftery AE. Bayes factors. J Amer Stat Ass. 1995;90:773-95.

79. Bielejec F, Rambault A, Suchar MA, Lemey P. SPREAD: spatial phylogenetic reconstruction of evolutionary dynamics. Bioinformatics. 2001;27:2910-2.

80. Yu Y, Harris AJ, He X. S-DIVA (statistical dispersal-Vicariance analysis): a tool for inferring biogeographic histories. Mol Phyl Evo. 2010;56:848-50.

81. Yu Y, Harris AJ, Xingjin H. RASP version 2.1b. 2001; Retrieved from http:// mnh.scu.edu.cn/soft/blog/RASP

82. Yu Y, Harris AJ, Blair C, He X. RASP (reconstruct ancestral state in phylogenies): a tool for historical biogeography. Mol Phyl Evo. 2015;87:46-9.

83. Tajima F. Statistical method for testing the neutral mutation hypothesis by DNA polymorphism. Genetics. 1989;123:585-95.

84. Fu Y-X. Statistical tests of neutrality of mutations against population growth hitchhiking and background selection. Genetics. 1997;147:915-25.

85. Rogers AR, Harpending H. Population growth makes waves in the distribution of pairwise genetic differences. Mol Bio Evo. 1992;9:552-69.

86. Excoffier L, Laval G, Schneider S. Arlequin (version 3.0): an integrated software package for population genetics data analysis. Evo Bioinfor Online. 2005:1:47.

87. Slatkin M, Hudson RR. Pairwise comparisons of mitochondrial DNA sequences in stable and exponentially growing populations. Genetics. 1991; 129:555-62.
88. Ray N, Currat M, Excoffier L. Intra-deme molecular diversity in spatially expanding populations. Mol Bio Evo. 2003;20:76-86.

89. Creer S, Thorpe RS, Malhotra A, Chou WH, Stenson AG. The utility of AFLPS for supporting mitochondrial DNA phylogeographical analyses in the Taiwanese bamboo viper, Trimeresurus stejnegeri. J Evol Biol. 2004;17:100-7.

90. Lin CC. Geology and ecology of Taiwan prehistory. Asian Perspect. 1963;7: 203-2013.

91. Jang-Liaw N-H, Lee T-H, Chou W-H. Phylogeography of Sylvirana latouchii (Anura, Ranidae) in Taiwan. Zool Sci. 2008;25:68-79.

92. Zhong J, Liu Z-Q, Wang Y-Q. Phylogeography of the rice frog, Fejervarya multistriata (Anura: Ranidae), from China based on mtDNA D-loop sequences. Zool Sci. 2008;25:811-20.

93. Sakka H, Quéré JP, Kartavtseva I, Pavlenko M, Chelomina G, Atopkin D, Bogdanov A, Michaux J. Comparative phylogeography of four Apodemus species (Mammalia: Rodentia) in the Asian Far East: evidence of quaternary climatic changes in their genetic structure. Biol J Linn Soc. 2010;100:797-821.

94. Blundell GM, Ben-David M, Groves PR, Bowyer T, Geffend E. Kinship and sociality in coastal river otters: are they related? Behav Ecol. 2004;15:705-14.

95. Gompper ME. Foraging costs and benefits of coati (Nasua narica) sociality and asociality. Behav Eco. 1996;7:254-63.

96. Gompper ME, Wayne RK. Genetic relationships among individuals within carnivore societies. In: Gittleman JL, editor. Carnivore behavior, ecology, and evolution, vol. 2. Ithaca. Cornell University press; 1996. p. 429-52.

97. Woo DG. A study of ecological characteristics and conservation of yellowthroated marten (Martes flavigula) in temperate forest of Korea. PhD dissertation. South Korea: Seoul National University; 2014.

98. Saunders G, Coman B, Kinnear J, Braysher M. Managing vertebrate pests: foxes. Canberra: Australian Government Printing Service; 1995.

99. Inoue T, Nonak N, Mizuno A, Morishima Y, Sato H, Katakura K, Oku Y. Mitochondrial DNA phylogeography of the red fox (Vulpes vulpes) in northern Japan. Zool Sci. 2007;24:1178-86.

100. Oishi T, Uraguchi K, Takahashi K, Masuda R. Population structures of the red fox (Vulpes vulpes) on the Hokkaido Island, Japan, revealed by microsatellite analysis. J Heredity. 2011;102:38-46.

101. Kim YK, Hong YJ, Min MS, Kim KS, Kim YJ, Voloshina I, Myslenkov A, Smith GJ, Cuong ND, Tho HH, Han SH, Yang DH, Kim CB, Lee $H$. Genetic status of Asiatic black bear (Ursus thibetanus) reintroduced into South Korea based on mitochondrial DNA and microsatellite loci analysis. J Hered. 2011;102:165-74.

102. Sato JJ. A review of the processes of mammalian faunal assembly in Japan insights from molecular phylogenetics. In: Motokawa M, Kajihara H, editors. Species Diversity of Animals in Japan. Japan: Springer; 2016. p. 49-116.

103. Tada R. Land bridge between Japan and the Asian continent during the last glacial period. In: Koizumi I, Tanaka K, editors. Ocean and civilization. Tokyo: Askura; 1995. p. 31-48.

104. Matsui H, Tada R, Oba T. Low-salinity isolation event of the Japan Sea in response to eustatic sea-level drop during the LGM: reconstruction based on salinity-balance model. Quat Res. 1998;37:221-33.

105. Dobson M, Kawamura Y. Origin of the Japanese land mammal fauna: allocation of extant species to historically-based categories. Quat Res. 1998; 37:385-95.

106. Keally CT. Japanese Pleistocene Landbridges and the Earliest Watercraft. 2005. http://www.t-net.ne.jp/ keally/MiddlePalaeol/landbridges.html. Accessed 20 Jan 2018.

107. Tamada T, Kurose N, Masuda R. Genetic diversity in domestic cats Felis catus of the Tsushima Islands, based on mitochondrial DNA cytochrome b and control region nucleotide sequences. Zool Sci. 2005;22:627-33.

108. Nogués-Bravo Rodriguez D, Hortal J, Batra P, Araujo MB. Climate change, humans, and the extinction of the woolly mammoth. PLoS Biol. 2008. https://doi.org/10.1371/journal.pbio.0060079. Accessed Sept 2018.

109. Horreo JL, Palacín C, Alonso JC, Milá B. A link between historical population decline in the threatened great bustard and human expansion in Iberia: evidence from genetic and demographic data. Biol J Linn Soc. 2013;110: 515-27.

110. Ahn S-M. The emergence of rice agriculture in Korea: Archaeobotanical perspectives. Archaeol Anthropol Sci. 2010;2:89-98.

111. Silva F, Stevens CJ, Weisskopf A, Castillo C, Qin L, Bevan A, Fuller DQ. Modelling the Geographical Origin of Rice Cultivation in Asia Using the Rice Archaeological Database. PlosOne. 2015. https://doi.org/10.1371/journal. pone.0137024 